\title{
IDENTIFICAÇÃO DAS PRINCIPAIS DISCUSSÕES ENTRE A ARQUIVOLOGIA E A GESTÃO ELETRÔNICA DE DOCUMENTOS
}

\author{
NADIANE CARLA DE OLIVEIRA SILVA* \\ ROBERTO LOPES DOS SANTOS JUNIOR ${ }^{* *}$
}

\begin{abstract}
RESUMO
Análise sobre o estado da arte das discussões feitas pela Arquivologia e Ciência da Informação sobre a Gestão Eletrônica de Documentos - GED, por meio de levantamento quantitativo e bibliográfico de artigos científicos em oito periódicos, sendo quatro na área de Arquivologia (Acervo, Ágora, Archeion Online e Informação Arquivística) e quatro em Ciência da Informação (Encontros Bibli, Informação \& Sociedade, Perspectivas em Ciência da Informação e TransInformação). Da coleta de dados, compreende-se publicações no período de 1985 a 2016, onde foram selecionados sessenta e dois trabalhos, considerando cinco terminologias: Tecnologia e Sociedade, Avanços Tecnológicos, Preservação de Documentos, Certificação Digital e Gestão Eletrônica de Documentos. Percebeu-se o período a partir de 2012 como o mais produtivo sobre o tema, com a terminologia preservação como a mais discutida e abordada tanto na Arquivologia como na Ciência da informação. Conclui-se que a Gestão Eletrônica de Documentos tem sido discutida e constituída ao longo dos últimos anos pela Arquivísitica, derivada dos avanços tecnológicos e seus desafios, sendo acessível e estruturada para uma conveniente gestão da informação pelo arquivista.
\end{abstract}

PALAVRAS-CHAVE: Gestão Eletrônica de Documentos. Arquivologia. Tecnologia.

ANALYSIS ABOUT THE STATE OF ART OF DISCUSSIONS BETWEEN ARCHIVAL SCIENCE AND ELECTRONIC MANAGEMENT OF DOCUMENTS

\begin{abstract}
Analysis about the State of the art of the discussions about Electronic Management of Documents made by Archival and Information Science, based on bibliographic and quantitative study in scientific articles in eight journals, four in archival science (Acervo, Ágora,
\end{abstract}

\footnotetext{
Graduada pela Faculdade de Arquivologia na Universidade Federal do Pará. Graduada pela Faculdade de Biblioteconomia na Universidade Federal do Pará.

* Professor adjunto da Faculdade de Arquivologia pela Universidade Federal do Pará. Doutor em Ciência da informação pelo convênio Instituto Brasileiro de Informação em Ciência e Tecnologia/Universidade Federal do Rio de Janeiro. Mestre em Ciência da Informação pelo convênio Instituto Brasileiro de Informação em Ciência e Tecnologia/Universidade Federal Fluminense.
} 
Archeion Online e Informação Arquivística) and four in information science (Encontros Bibli, Informação \& Sociedade: Estudos, Perspectivas em Ciência da Informação e TransInformação). It was separated publications between 1985 and 2016, which sixty-two was selected considering five specific terminologies: Technology and Society, Technological Advances, Document Preservation, Digital Certification and Electronic Document Management. It was perceived that the period after 2012 and the preservation topic was the most produced by Archival and Information Science. This research concludes that the Electronic Management of Documents has been discussed and established over the years, derived from the consequences of technological advances and its challenges, being accessible and structured to a convenient management of information.

KEYWORDS: Electronic Document Management. Archival Science. Technology.

\section{INTRODUÇÃO}

O arquivista tem, entre suas responsabilidades, o apropriado emprego dos princípios arquivísticos para a custódia e utilização dos arquivos na sociedade. Nas últimas décadas, a inserção da tecnologia no mercado de trabalho vem a desafiar este profissional, estimulando sua renovação, devendo obter significativo conhecimento da área tecnológica para se alinhar à realidade contemporânea. (SANTOS, 2014).

Nessa nova realidade a qual o arquivista está inserido, a Gestão Eletrônica de Documentos (GED) aparece como instrumento capaz de conduzir as organizações a eficiente estruturação de suas informações, convergindo sua origem, controle, guarda e destino, por meio do uso das tecnologias, que promovem melhor desempenho e controle no acesso às informações processadas digitalmente. (SANTOS, 2014). Consolidado a partir dos anos 1990, o tema coloca-se como um dos norteadores de revitalização da prática arquivística no século 21. (MILLAR, 2017).

Qual o estado da arte das discussões ligadas a Gestão Eletrônica de Documentos na Arquivologia brasileira? Quais tendências são encontradas em relação a essa análise? Para responder esses questionamentos, a presente pesquisa analisou, a partir de levantamento quantitativo e bibliográfico, as temáticas relacionadas a Gestão Eletrônica de Documentos discutidas em periódicos nas áreas de Arquivologia (Acervo, Ágora, Archeion Online, Informação Arquivística) e Ciência da Informação (Encontros Bibli, Informação \& Sociedade, Perspectivas em Ciência da Informação 
e Trans Informação). A pesquisa tem como objetivo a contribuição para futuras pesquisas relacionadas à temática, reunindo dados quantitativos sobre o leque de publicações que versam sobre o tema, oportunizando uma visão geral sobre a Gestão Eletrônica de Documentos na visão dos pesquisadores ligados a Arquivologia e áreas correlatas.

Inicialmente, a pesquisa fez breve contextualização sobre o papel da tecnologia na sociedade contemporânea. Posteriormente, foi discutido as definições e principais características da Gestão Eletrônica de Documentos. Após essas análises, descreveu-se a metodologia e procedimentos aplicados no trabalho, e o resultado do levantamento nos periódicos selecionados.

\section{O ARQUIVISTA E OS AVANÇOS TECNOLÓGICOS NA CONTEMPORANEIDADE}

Com o processo de globalização, a partir do final do século $X X$, a sociedade mostra-se sujeita a contínuas transformações, identificadas na intensa participação tecnológica na produção e disseminação de informações. (BONATO, 2004).

Para Ferreira (2003), a revolução tecnológica na contemporaneidade pode ser caracterizada em dois aspectos: centralidade em processos, envolvendo todas as esferas da atividade humana, e informação, como insumo e resultado principal desses processos.

Após a $2^{\circ}$ Guerra Mundial, a tecnologia, por meio dos computadores, passou, gradativamente, do uso militar para o dia a dia das instituições, sejam elas públicas ou privadas. Até a década de 1970, o uso desses equipamentos estava limitado ao uso de especialistas, devido a necessidade de entendimento sobre hardware e software, uma época em que os profissionais ficavam isolados nos Centro de Processamento de Dados - CPD. (RONDINELLI, 2005).

Rondinelli (2005) afirma que, a partir dos anos 1980, os computadores pessoais marcaram o fim da exclusividade desses Centros de Processamento de Dados - CPD. A disseminação do uso dos microcomputadores deveu-se a chegada de softwares "amigáveis" (custos mais baixos), facilitada com o advento da tecnologia de rede, que evoluiu rapidamente de redes locais à globais.

O avanço da internet, na década de 1990, constituiu-se como meio importante no atendimento aos usuários, garantindo a disseminação da informação. (NEGREIROS; DIAS, 2007). Segundo 
Castells (2016), a tecnologia da informação contempla um conjunto convergente de tecnologias criadas pelo homem que geram implicações sociais, políticas, econômicas e culturais na sociedade.

Na realidade profissional contemporânea

[...] os profissionais da informação foram profundamente atingidos e, entre eles, os arquivistas. Tal informação se fundamenta no fato de que o avanço tecnológico mudou radicalmente os mecanismos de registro e de comunicação da informação nas instituições e, consequentemente, seus arquivos também mudaram. (RONDINELLI, 2005, p. 24).

Historicamente, a junção das temáticas Arquivologia e Informática registra-se, pela primeira vez, em congresso promovido pelo Conselho Internacional dos Arquivos - CIA em 1964. Nesta ocasião, os participantes demonstraram interesse apenas localizado ao assunto, pois os arquivistas, nessa época, viam o computador somente como um instrumento a ser usado para fins estatísticos e fiscais. A única exceção foi o Arquivo Nacional dos Estados Unidos, que usava, ocasionalmente, computadores para a recuperação da informação. Esse desinteresse se deveu também tanto ao conservadorismo profissional como pela ausência de recursos financeiros nesses equipamentos. (RONDINELLI, 2005).

$\mathrm{Na}$ década de 1980, se registram dois acontecimentos importantes em relação a Arquivologia e Informática. O primeiro, em pesquisa internacional promovida pelo Comitê de Automação do Conselho Internacional dos Arquivos, em 1985, que tratou da aplicação da informática à gestão arquivística. O segundo, em discussões aprofundadas sobre o gerenciamento de informações eletrônicas ocorridas no Congresso Internacional de Arquivos realizado em 1988, em Paris. (NEGREIRO, DIAS, 2007; RONDINELLI, 2005). Seria nos anos 1990 que a relação teórica entre a Arquivologia e informática ganharia contornos mais aprofundados, exemplificado com o surgimento de terminologias como "documentos eletrônicos" e "arquivos nato digitais." (THOMAZ, 2006; RONDINELLI, 2005).

No Brasil, na década de 1970, o diálogo entre a Arquivologia e a Informática apresentava um quadro embrionário, que continuaria nas décadas seguintes, mostrando-se pouco aprofundado e muitas vezes a reboque de outros profissionais da Informação. Somente a partir da década de 1990 surgiram as primeiras publicações relacionando, de forma aprofundada, a Arquivologia com os documentos eletrônicos e sua gestão. (THOMAZ, 2006; NEGREIROS, DIAS, 2007). 
Thomaz (2006) menciona que, no século 21, há maior quantidade de trabalhos sobre a relação entre a Arquivologia e os documentos eletrônicos, visualizada em artigos nas revistas Arquivo \& Administração, Acervo, Ágora e Arquivo Público Mineiro - APM, e da produção dos autores Humberto Innarelli, Daniel Flores, Roseli Rondinelli, Claudia Lacombe, Vanderlei dos Santos, Eduardo Valle, entre outros.

\section{GESTÃO ELETRÔNICA DE DOCUMENTOS - GED}

Da necessidade das organizações em adotar políticas para a gestão documental, surgem os sistemas de informação e ferramentas tecnológicas ligadas ao suporte no tratamento da informação, identificadas como Gestão Eletrônica de Documentos GED. (ELIAS, 2012).

No Brasil, a partir dos anos 1990, foram estabelecidas normativas legais em relação ao tema, com especificidades em setores das esferas federais, estaduais e municipais, em âmbito público e privado. Destaca-se o Conselho Nacional de Arquivos CONARQ como o disseminador de subsídios científicos às pesquisas e discussões na área do Gerenciamento Eletrônico de Documentos desde o fim dos anos 1990. (SANTOS, 2014).

Define-se Gestão Eletrônica de Documentos, segundo o CONARQ (2011a, 2011b), como conjunto de tecnologias utilizáveis para se organizar informações não estruturadas de determinado órgão ou instituição, podendo englobar tecnologias de digitalização, automação de fluxos de trabalho (workflow), processamento de formulários, indexação, gestão de documentos, repositórios, entre outras, podendo ser dividido em quatro funcionalidades: captura, gerenciamento, armazenamento e distribuição, especificados abaixo.

A captura consiste em declarar um documento como um documento arquivístico, incorporando-o ao sistema de gestão arquivística por meio das seguintes ações: registro, classificação, indexação, atribuição de restrição de acesso e arquivamento [...] O gerenciamento, caracterizado na forma e no controle das informações prezando segurança e fidedignidade aos documentos arquivístico [...] O armazenamento deve garantir a autenticidade e o acesso aos documentos pelo tempo estipulado na tabela de temporalidade e destinação [...] A distribuição como forma de destinação do documento arquivístico. (CONARQ, 2011a, p. 26-29).

Como características da Gestão Eletrônica de Documentos, Cattelan (2000) cita quatro principais: a) trabalhar com arquivos 
digitais, permitindo maior portabilidade e facilidade em migrar informações; b) economizar espaço físico, compreendendo uma redução na capacidade de armazenamento em mídias; c) preservar originais, reduzindo o manuseio do arquivo físico e garantindo a integridade do original; d) facilitar acesso aos documentos, garantindo acesso simultâneo a diversos usuários com níveis e privilégios atribuídos à leitura do documento.

Elias (2012) e Schäfer e Lima (2012) comentam sobre vantagens e desvantagens da implementação de políticas de Gestão Eletrônica de Documentos. Como aspecto positivo, essa gestão consiste em: otimizar as atividades, agilizar processos de disseminação e o acesso à informação, confiabilidade e eficiência, redução em áreas de arquivamento e no tempo de recuperação da informação, rápida atualização de dados, acesso simultâneo em redes de informação, cópias de segurança, diminuição no volume documental em suporte físico, preservação de originais, redução de custos, qualidade, aumento na capacidade de armazenamento e controle da informação. Do lado negativo, se observa: alteração de mídias, aspectos legais de documentos digitais, recursos tecnológicos obsoletos e uma obrigatoriedade na existência de equipamentos e softwares para recuperação da informação.

Objetivando dar efetividade a Gestão Eletrônica de Documentos, o Sistema Informatizado de Gestão Arquivística de Documentos - SIGAD, software desenvolvido para registro e controle documental, atua como suporte à gestão arquivística, seja ela para documentos em formatos físicos e/ou eletrônicos, da captura a destinação final. O sistema oferece a padronização de procedimentos arquivísticos em documentos, integração simultânea da informação na área tecnológica, além de garantir a confiabilidade, autenticidade e acesso. (CONARQ, 2011b).

Nos últimos, anos a Gestão Eletrônica de Documentos expandiu seu campo de análise a questões relacionadas no âmbito da preservação do objeto/suporte digital e eletrônico e da certificação digital, referente a autenticidade das informações advindas desses documentos.

A Preservação Digital, segundo Grácio, Fadel e Valentim (2013), envolve elementos que devem integrar a preservação física, lógica e intelectual dos objetos digitais, obedecendo padrões globais e inseridas nas políticas institucionais, constituindo-se em atividades necessárias para a garantia de acesso, integridade e autenticidade da informação.

Dentre as estratégias mais utilizadas na Preservação Digital citam-se a migração, ou "procedimento de transferência do objeto 
digital para um suporte/plataforma (podendo abranger hardware, software e formatos) de geração tecnológica subsequente, permitindo que as informações estejam acessíveis ao longo do tempo"; emulação, que "[...] baseia-se na utilização de um software (denominado emulador) que tem a função de reproduzir o comportamento de um determinado hardware e/ ou software em uma plataforma com a qual não era compatível."; e encapsulamento, que "[...] visa a preservação conjunta do objeto digital, com as informações necessárias ao futuro desenvolvimento de funcionalidades para sua conversão e visualização". A utilização de uma ou a combinação delas poderá dar suporte à estratégia de preservação de documentos de determinada organização. (SCHAFER, CONSTANTE, 2012, p. 111-114).

A tecnologia empregada nas estratégias organizacionais permitiu também a eficiência do processamento e acesso das informações. Dessa complexidade, houve necessidade de se adotar políticas para a garantia de segurança, autenticidade e integridade de documentos, sobretudo aos de origem eletrônica. A partir dessa premissa, a certificação digital surge como instrumento que permite a identificação segura no ambiente digital por meio de diretrizes e o uso de códigos digitais, denominado criptografia. O certificado digital caracteriza-se como um documento, a partir de software personalizado, que funciona como uma identidade virtual que permite a identificação segura (chave pública) do autor de uma mensagem ou transação eletrônica, gerado e assinado por uma autoridade certificadora que associa uma entidade a um par de chaves criptográficas. (BRASIL, 2017; DORNELES; CORRÊA, 2013; ALONSO; FERNEDA; BRAGA, 2011).

A regulamentação das atividades de certificação digital no Brasil, via Medida Provisória n. 2.200-2/2001, que institui o ICP-Brasil, garantiu transações eletrônicas com maior segurança e incentivou a utilização da internet como meio para a realização de negócios, bem como meio de comunicação alternativo para a disponibilização de diversos serviços com agilidade, facilidade de acesso e redução de custos. (MIGLIAVACCA; DUTRA, 2014; DORNELES; CORREAA, 2013; BRASIL, 2017).

Por fim, a Gestão Eletrônica de Documentos foca sua análise sobre os avanços tecnológicos, com o prazo de obsolescência das tecnologias cada vez menor, ressaltando a necessidade do arquivista de uma constante e ininterrupta capacidade de atualização sobre os principais hardwares, softwares e sistemas digitais de informação disponíveis (SANTOS, FLORES, 2020), 
além do impacto dessas tecnologias sobre a sociedade contemporânea, no qual, segundo palavras de Cook (2012, 2013), consolida o surgimento de um "arquivista pós moderno".

\section{PROCEDIMENTOS METODOLÓGICOS}

Este estudo é caracterizado como bibliográfico, onde foram analisados materiais disponibilizados na internet, e de caráter quantitativo, identificados tanto na coleta de informação, como em seu tratamento por meio de técnicas estatísticas. Todas essas avaliações são feitas com a ajuda de indicadores, utilizando-se as incidências de palavras-chaves e os autores das revistas em quadros e tabelas, que tendem a traduzir, objetivamente, os resultados estatísticos. (HAYASHI, 2012). A pesquisa do tipo bibliográfica foi escolhida por facilitar o levantamento e construção de perspectivas a partir de materiais publicados e relevantes à comunidade acadêmica, respeitado $o$ acesso livre e a disponibilização de tais informações.

A pesquisa deu-se, inicialmente, por meio de levantamento em periódicos eletrônicos nas áreas de Arquivologia e Ciência da Informação, com o corte de quatro para cada área.

Em relação a Arquivologia foram selecionados periódicos que estejam em atividade, sendo escolhidos as revistas Acervo ${ }^{1}$ (Arquivo Nacional), Ágora ${ }^{2}$ (Arquivo Público do Estado de Santa Catarina/ Universidade Federal de Santa Catarina), Informação Arquivística ${ }^{3}$ (Associação dos Arquivistas do Estado do Rio de Janeiro) e Archeion $^{4}$ (Universidade Federal da Paraíba). Em relação a Ciência da Informação o critério baseou-se em revista consolidadas, identificadas na alta classificação da base Qualis ${ }^{5}$, por essa base como A1 e A2: Encontros Bibli ${ }^{6}$ (Universidade Federal

1 Em atividade desde 1986. Endereço eletrônico: http://revista.arquivonacional. gov.br/index.php/revistaacervo. ISSN: 2237-8723.

2 Em atividade desde 1985. Endereço eletrônico: https://agora.emnuvens. com.br/ra/index. ISSN: 0103-3557

3 Em atividade desde 2012. Endereço eletrônico: http://www.aaerj.org.br/ojs/ index.php/informacaoarquivistica/. ISSN: 2316-7300

$4 \mathrm{Em}$ atividade desde 2013. Endereço eletrônico: http://periodicos.ufpb. br/index.php/archeion/index. ISSN: 2318-6186

${ }^{5}$ Qualis Periódicos: sistema de avaliação de publicações científicas e de classificação de periódicos instituído pela Coordenação de Aperfeiçoamento de Pessoal do Ensino Superior - CAPES, desde 1977, e visa qualificar a produção intelectual no país, agregando o aspecto quantitativo e qualitativo. A avaliação baseada no levantamento é a disponibilizada em 2016.

6 Em atividade desde 1996. Endereço eletrônico: <https://periodicos. ufsc.br/index.php/eb>. ISSN: 1518-2924. 
de Santa Catarina), Perspectivas em Ciência da Informação ${ }^{7}$ (Universidade Federal de Minas Gerais), Transinformação ${ }^{8}$ (PUCCAMP) e Informação \& Sociedade ${ }^{9}$ (Universidade Federal da Paraíba). O período analisado foi entre o primeiro número da revista disponível na internet até o último publicado em 2016.

Dentre esses periódicos, foram selecionados, como amostra, artigos científicos observando terminologias específicas como: Tecnologia e Sociedade, Avanços Tecnológicos, Preservação de Documentos, Certificação Digital, e Gestão Eletrônica de Documentos. A escolha dessas terminologias deveu-se a relação intrínseca delas com o tema de estudo, além de contribuírem com subsídios e definições nas pesquisas dessa temática.

Entende-se a seguinte relação com tais terminologias: Tecnologia e Sociedade, por envolver diálogos e fatos contemporâneos à arquivística; Avanços Tecnológicos, como campo promotor do objeto de pesquisa; Preservação de Documentos e Certificação Digital, por serem particularidades e aplicações da GED; e Gestão Eletrônica de Documentos, haja vista dar título a esse trabalho.

Os resultados tiveram como corte a lista de assuntos tratados nos títulos, palavras-chave, resumos, introdução e capítulos iniciais, e os autores, e, obtendo um relacionamento entre os dados e a construção dos indicadores e resultados.

\subsection{Resultados}

Da coleta de dados, compreendendo as publicações online disponíveis do período entre 1985 a 2016, foi considerado, inicialmente, oitenta e cinco artigos científicos, dos quais 23 foram descartados por não contemplar as terminologias almejadas para este estudo. Desses, $53 \%$ encontram-se em periódicos de Ciência da Informação e, na Arquivologia, 46,7\%. Assim delimitado, expõe-se a distribuição dos periódicos/área em três períodos de análise (tabela 1).

7 Em atividade desde 1996. Endereço eletrônico: <http://portaldeperiodicos. eci.ufmg.br/index.php/pci>. ISSN: 1981-5344

$8 \mathrm{Em}$ atividade desde 1989. Endereço eletrônico: <http://periodicos.puccampinas.edu.br/seer/index.php/transinfo>. ISSN: 2318-0889.

$9 \mathrm{Em}$ atividade desde 1991. Endereço eletrônico: <http://www.ies.ufpb. br/ojs2/index.php/ies>. ISSN: 1809-4783 
Tabela 1 - Quantidade de periódicos distribuídos por área em cada quinquênio.

\begin{tabular}{|c|c|c|c|c|c|c|c|c|}
\hline \multirow[b]{2}{*}{ Periódicos/Área } & \multicolumn{6}{|c|}{ Quantidade de acervo/Quinquênio } & \multirow[b]{2}{*}{$\begin{array}{l}\text { Total } \\
\text { Geral }\end{array}$} & \multirow[b]{2}{*}{$\%$} \\
\hline & $\begin{array}{c}2016 \\
a \\
2012\end{array}$ & $\%$ & $\begin{array}{c}2011 \\
a \\
2007\end{array}$ & $\%$ & $\begin{array}{c}2006 \\
a \\
1985^{\star}\end{array}$ & $\%$ & & \\
\hline \multicolumn{9}{|c|}{ ARQUIVOLOGIA } \\
\hline Acervo & 5 & 23.8 & 1 & 25 & 2 & 50 & 8 & 27,5 \\
\hline Ágora & 7 & 33,3 & 3 & 75 & 2 & 50 & 12 & 41,3 \\
\hline Archeion Online & 3 & 14,3 & - & - & - & - & 3 & 10,3 \\
\hline $\begin{array}{l}\text { Informação } \\
\text { Arquivistica }\end{array}$ & 6 & 25,5 & - & - & - & - & 6 & 20,6 \\
\hline Subtotal (1) & 21 & 100 & 4 & 100 & 4 & 100 & 29 & $46,7^{*}$ \\
\hline \multicolumn{9}{|c|}{ CIÊNCIA DA INFORMAÇÃO } \\
\hline Encontros Bibli & 6 & 40 & 4 & 44,4 & 2 & 28,5 & 12 & 36,3 \\
\hline $\begin{array}{l}\text { Informação \& } \\
\text { Soc.: Estudos }\end{array}$ & 3 & 20 & 5 & 55,5 & 2 & 28,5 & 10 & 30,3 \\
\hline $\begin{array}{l}\text { Perspectivas em } \\
\text { C. Informação }\end{array}$ & 6 & 40 & 2 & 22,2 & 1 & 14,2 & 9 & 27,2 \\
\hline TransInformação & - & - & - & - & 2 & 28,5 & 2 & 6 \\
\hline Subtotal (2) & 15 & 100 & 9 & 100 & 7 & 100 & 33 & $53,2^{*}$ \\
\hline Total Geral & 36 & 58 & 14 & 22,5 & 12 & 19,2 & 62 & 100,0 \\
\hline
\end{tabular}

Fonte: Autores da pesquisa, 2017. *sobre o total de 62 de artigos.

Considerando os sessenta e dois trabalhos selecionados, percebe-se que a Ciência da Informação tem maior quantidade de artigos publicados, trinta e três, e na Arquivologia com o total de 29 artigos. No âmbito da Arquivologia, o periódico Ágora, com doze trabalhos, foi o que mais apresentou artigos ligados a temática, e na Ciência da Informação, a revista Encontros Bibli, também com (12 artigos, a que mais produziu trabalhos sobre o tema, seguida pela revista Informação \& Sociedade (10 trabalhos). Percebeu-se também, em ambas as áreas, considerável crescimento de pesquisas no último quinquênio (2012 a 2016), de longe o mais produtivo sobre a temática (36 trabalhos, com $58 \%$ de produção sobre o tema, contra 26 artigos entre 1985 e 2011).

$\mathrm{Na}$ tabela a seguir analisou-se como as temáticas utilizadas foram distribuídas nos periódicos em Arquivologia e Ciência da Informação. 
Tabela 2 - Quantidade de periódicos/área por terminologia utilizadas à coleta de informações da pesquisa, período de 1985 a 2016.

\begin{tabular}{|c|c|c|c|c|c|c|}
\hline \multirow{3}{*}{ Terminologia } & \multicolumn{4}{|c|}{ Quantidade de Periódico/Área } & \multirow{3}{*}{$\begin{array}{l}\text { Total } \\
\text { Geral }\end{array}$} & \multirow{3}{*}{$\%$} \\
\hline & \multicolumn{2}{|c|}{ Arquivologia } & \multicolumn{2}{|c|}{$\begin{array}{l}\text { Ciência da } \\
\text { Informação }\end{array}$} & & \\
\hline & Quantidade & $\%$ & Quantidade & $\%$ & & \\
\hline $\begin{array}{c}\text { Avanços } \\
\text { Tecnológicos }\end{array}$ & 3 & 10,3 & 9 & 27,2 & 12 & 19,3 \\
\hline $\begin{array}{l}\text { Certificaçãa } \\
\text { Digital }\end{array}$ & 3 & 10,3 & 1 & 3 & 4 & 6,4 \\
\hline $\begin{array}{c}\text { Gestão } \\
\text { Eletrônica de } \\
\text { Documentos } \\
\end{array}$ & 9 & 31 & 1 & 3 & 10 & 16,1 \\
\hline $\begin{array}{l}\text { Preservação de } \\
\text { Documentos }\end{array}$ & 13 & 44,8 & 21 & 63,6 & 34 & 54,8 \\
\hline $\begin{array}{l}\text { Tecnologia e } \\
\text { Sociedade }\end{array}$ & 1 & 3,4 & 1 & 3 & 2 & 3,2 \\
\hline Total Geral & 29 & 100,0 & 33 & 100,0 & 62 & 100,0 \\
\hline
\end{tabular}

Fonte: Autores da pesquisa, 2017.

Nessa amostra, foi percebido que a terminologia em maior quantidade nos artigos analisados foram os relacionados a Preservação de Documentos Eletrônicos (34 artigos), tanto em periódicos ligados a Arquivologia (treze artigos) quanto em Ciência da informação (vinte e um trabalhos). Nos menos analisados, citam-se as terminologias Tecnologia e Sociedade (dois artigos) e Certificação Digital (quatro trabalhos). Cabe ressaltar que, nos periódicos pesquisados na Arquivologia, há considerável número de pesquisas relacionadas a Gestão Eletrônica de Documentos (10) e, na Ciência da Informação, a temática Avanços tecnológicos (nove trabalhos).

No quadro 1, foram identificados os autores mais produtivos ligados a Gestão Eletrônica de Documentos. 
Quadro 1 - Autores com mais produção científica nos periódicos pesquisados.

\begin{tabular}{|c|c|c|c|}
\hline Autores/Área & Autoria Principal & Coautoria & $\begin{array}{c}\text { Total de } \\
\text { Participações }\end{array}$ \\
\hline \multicolumn{4}{|c|}{ Arquivologia } \\
\hline ELIAS, E. D. & 2 & - & 2 \\
\hline FLORES, D. & 1 & 3 & 4 \\
\hline MARTINS, D. F. & 2 & - & 2 \\
\hline ROCHA, C. L. & 3 & - & 3 \\
\hline SANTOS, H. M. & 2 & 1 & 3 \\
\hline SILVA, M. & - & 2 & 2 \\
\hline VITAL, L. P. & 2 & - & 2 \\
\hline Subtotal (1) & 12 & 6 & 18 \\
\hline \multicolumn{4}{|c|}{ Ciência da Informação } \\
\hline BAHIA, E. M. S. & 2 & - & 2 \\
\hline FLORES, D. & - & 4 & 4 \\
\hline SALES, L. F. & 1 & 1 & 2 \\
\hline SANTOS, H. M. & 4 & - & 4 \\
\hline SAYÃO, L. F. & 2 & - & 2 \\
\hline Subtotal (2) & 9 & 5 & 14 \\
\hline Total Geral & 20 & 11 & 32 \\
\hline
\end{tabular}

Fonte: Autores da pesquisa, 2017.

Relacionado aos autores com maior quantidade de artigos, observamos Daniel Flores, com oito participações, tendo 4 na área de Arquivologia e 4 em Ciência da Informação, seguido de Henrique Machado dos Santos, com sete participações, três em Arquivologia e quatro em Ciência da Informação. Foi percebido que Flores contribuiu mais como coautor e Santos como autor principal (ver apêndice), os dois sendo os únicos autores com graduação em Arquivologia entre os de maior produção. Daniel Flores atualmente atua como professor na Universidade Federal Fluminense, em Niterói, e Henrique Machado dos Santos como arquivista na Universidade Federal do Rio Grande, ambos membros do grupo de pesquisa Gestão Eletrônica de Documentos Arquivísticos (GED/A), pela Universidade Federal de Santa Maria. 
Do total de 32 participações, percebe-se que grande parte dos autores, sete dos dez listados, produziram literaturas em periódicos na área de Arquivologia, totalizando 18 artigos.

\subsection{Breve panorama dos trabalhos levantados}

Durante a pesquisa, analisando a evolução das terminologias atribuídas, encontramos, inicialmente, em Tecnologia e Sociedade, experiências de uso da tecnologia no âmbito institucional, na implementação de projetos de digitalização de acervo no Núcleo de Temática da Seca - NuT-Seca/UFRN (FREIRE et al, 2008) e outra no processo de recuperação de informações no ambiente virtual. (DANTAS; CORDULA; ARAÚJO, 2016).

Em Avanços Tecnológicos, pode-se observar a relação dos profissionais da informação diante da evolução tecnológica. Abreu (2016) e Martins (1996) retratam as práticas arquivísticas em sistemas informatizados e Martins (1997) reúne literaturas demonstrando a aplicabilidade de recursos tecnológicos na gestão documental. Já Sales e Sayão (2012) trazem a curadoria digital e seus impactos enquanto nova atividade de tratamento e representação da informação. Também foram identificadas contribuições sobre a inserção do arquivista no campo da gestão documental. (SILVA, 2016). Souza (2014), Negreiros e Dias (2008), e Cabral (2002) analisaram a formação e atuação profissional do arquivista às novas demandas profissionais.

Considerando as últimas décadas, onde os impactos da tecnologia são percebidos na sociedade contemporânea, na terminologia Gestão de Documentos Eletrônicos, encontramos os relatos de experiência dessa ferramenta nas organizações, aplicação e avaliação prática do uso e desenvolvimento de sistemas informatizados para documentos arquivísticos em formato eletrônico, como apresentado pelos autores Anjos e Felipe (2014), Vital e Azevedo Junior (2014), Elias (2012) e Flores e Lampert (2013). Outros, como Abreu (2014), Nascimento e Sousa (2015) e Schäfer e Lima (2012) realizaram discussões sobre a autenticidade e segurança da informação no processo de migração entre o ambiente físico para o digital, curiosamente não focando na certificação digital.

Foi percebido também a complexidade no gerenciamento de documentos, no qual envolve a necessidade da utilização, por meio de técnicas arquivísticas, de diversificados procedimentos à conservação e preservação da informação expressa, convertida e transmitida, seja ela por meio físico ou virtual. (CASTRO; CASTRO; 
GASPARIAN, 2007). Com a evolução tecnológica, esse gerenciamento evidencia o eficiente registro e controle da informação, assegurando aos usuários transparência e seguridade de forma organizada. (SANTOS; FLORES, 2016; CASTRO; CASTRO; GASPARIAN, 2007).

Em relação a terminologia Preservação de Documentos, identificou-se a necessidade pela garantia da longevidade dos documentos, e do acesso e preservação da informação digital. (LACOMBE; RONDINELLI, 2016; SANTOS; FLORES, 2015; OLIVEIRA, 2011; BESSER, 2010; ROCHA; SILVA, 2007). Dessa implementação, percebe-se em Santos Junior e Nunes (2016), a importância dessas estratégias, especificamente nos acervos em videogames, expandindo as técnicas convencionais de preservação.

Lampert (2016) e Fontana et al (2014) expõem estudos sobre ferramentas de repositório digital como uso dos softwares DSpace e Archivematica. Já Vital (2011) e Silva (2012) discutem o uso de formatos abertos como alternativa para a preservação em longo prazo, como o SEER e o PDF/A no gerenciamento arquivístico de documentos eletrônicos. Outra proposição, destacada por Bahia, Santos e Blattmann (2011), foca em levantamento quantitativo na base de dados Library and Information Science Abstract, conhecida como LISA. Costa e Caporalli (2014) relatam os resultados da execução do Projeto de Extensão Eletrônico, desenvolvido na Universidade Estadual de Londrina, como iniciativa de oferecer contribuições para a gestão e preservação digital, sendo atribuído características arquivísticas. Rocha e Silva (2004) citam a Carta para a Preservação do Patrimônio Arquivístico Digital Brasileiro, adaptação da mensagem produzida pela Unesco, em 2003, cujo objetivo consiste em conscientizar e ampliar discussões sobre o legado digital e sobre a confiabilidade das informações em formatos eletrônicos/digitais.

Por fim, no tópico Certificação Digital, a mesma foi apresentada como instrumento de autenticidade e confiabilidade, por meio de programas como, por exemplo, o Governo Eletrônico (e-gov), aplicado no Brasil. (MIGLIAVACCA; DUTRA, 2014; ALONSO; FERNEDA; BRAGA, 2011). Herkert Netto (2014) e Dorneles e Corrêa (2013) contextualizaram a aplicação dessas ferramentas na gestão arquivística de documentos, e Migliavacca e Dutra (2014) projetaram seu uso a partir de estudo de caso realizado no Tribunal Regional Eleitoral de Santa Catarina - TRE-SC. 


\section{CONSIDERAÇÕES FINAIS}

O presente trabalho consistiu na análise sobre a Gestão Eletrônica de Documentos, por meio de análise quantitativa de literatura, identificando as principais tendências de discussão na Arquivologia e Ciência da Informação.

A coleta de dados identificou que mais da metade das publicações produzidas estão no período entre 2012 e 2016, o que pode indicar a recente importância e consolidação do tema pela Arquivologia, e da produção considerável relacionada a terminologia Preservação de Documentos, podendo inferir, preliminarmente, que há considerável preocupação na salvaguarda da informação em meio eletrônico, ainda à guisa de maior aprofundamento. Em relação a Ciência da Informação possuir maior quantidade de artigos sobre a Gestão Eletrônica de Documentos, especula-se que o caráter interdisciplinar das pesquisas e de seus autores, somado ao número limitado de revistas ligadas a Arquivologia (e o caráter por vezes instável de publicação nesses periódicos) como possíveis razões para esse resultado.

Considerando o exposto, podemos observar que a Gestão Eletrônica de Documentos tem sido discutida e constituída ao longo das últimas décadas, derivada das consequências dos avanços tecnológicos e seus desafios, bem como o impacto e contribuição do profissional da informação, focado aqui no arquivista, nessa nova realidade organizacional. Apesar de compreendida como ferramenta tecnológica primordial para as organizações, seu uso, pela bibliografia analisada, ainda se restringe a particularidades, como na já citada preservação e conservação documental e, em menor medida, na certificação digital.

Esse estudo pôde identificar a Gestão Eletrônica de Documentos, a partir das análises abordadas, como tecnologia acessível e estruturada para uma conveniente gestão da informação, visualizando discussões contemporâneas sobre seu emprego nas organizações, servindo de base para levantamentos posteriores da Arquivologia brasileira sobre essa temática.

\section{REFERÊNCIAS}

ABREU, Jorge Phelipe Lira de. Aprender a ler entre bits: autenticidade em arquivos pessoais digitais. Acervo, Rio de Janeiro, v. 29, n. 2, p. 133-142, jul. /dez. 2016. 
ALONSO, Luiza Beth Nunes; FERNEDA, Edilson; BRAGA, Lamartine Vieira. Governo eletrônico e políticas públicas: análise sobre o uso da certificação digital no Brasil. Informação \& Sociedade: Estudos, João Pessoa, v. 21, n. 2, p. 13-24, maio/ago. 2011.

ANJOS, Clebson Leandro Beserra; FELIPE, André Anderson Cavalcante. Gestão documental em unidades de informação: uma análise do arquivo da Fundação Norte-Rio-Grandense de Pesquisa de Cultura - FUNPEC. Ágora, Florianópolis, v. 24, n. 49, p. 257-276, 2014.

BAHIA, Eliana Maria dos Santos; SANTOS, Raimundo Nonato Macedo dos; BLATTMANN, Ursula. Estudo bibliométrico sobre preservação digital: Library and Information Science Abstracts - LISA. Encontros Bibli, Florianópolis, v. 16, n. esp. 1 sem., p. 91-105, 2011.

BESSER, Howard. Longevidade digital. Acervo, Rio de Janeiro, v. 23, n. 2, p. 57-70, jul. /dez. 2010.

BONATO, Nailda Marinho da Costa. O uso das fontes documentais na pesquisa em história da educação e as novas tecnologias. Acervo, Rio de Janeiro, v. 17, n. 2, p. 85-110, jul. /dez. 2004.

BRASIL. Instituto Nacional de Tecnologia da Informação - ITI. Certificação digital. Disponível em: http://www.iti.gov.br/certificacao-digital/. Acesso em: 22 jun. 2017.

CABRAL, Ana Maria Rezende. Tecnologia digital em bibliotecas e arquivos. Transinformação, Campinas, v. 14, n. 2, p. 167-177, jul. /Dez. 2002.

CASTELLS, M. A sociedade em rede. $10^{\circ}$ ed. São Paulo: Paz e Terra, 2016.

CASTRO, Astréa de Moraes e; CASTRO, Andresa de Moraes e;

GASPARIAN, Danuza de Moraes e Castro. Arquivos: físicos e digitais.

Brasília: Thesaurus, 2007.

CATTELAN, Paulo. Winbusca-GED: construção do banco de dados do arquivo histórico para o memorial do Rio Grande do Sul. Ágora,

Florianópolis, v. 15, n. 31, p. 50-56, 2000.

CLOONAN, Michèle $\mathrm{V}$. Preservando documentos de valor permanente. In: EASTWOOD, Terry; MACNEIL, Heather (Org.). Correntes atuais do pensamento arquivístico. Tradução de Anderson Bastos Martins, Revisão de Heloísa Liberalli Belloto. Belo Horizonte: Editora UFMG, 2016. p. 107-134.

CONARQ - Conselho Nacional de Arquivos. e-ARQ Brasil: modelo de requisitos para sistemas informatizados de Gestão Arquivística de Documentos. Rio de Janeiro: Arquivo Nacional, 2011a.

. Orientação Técnica $n^{\circ}$ 1: orientações para contratação de SIGAD e serviços correlatos. 2011 b.

COOK, T. Arquivologia e Pós-modernismo: novas formulações para velhos conceitos. Informação Arquivística, Rio de Janeiro, v. 1, n. 1, p. 123-148, 2012. 
Moda absurda ou Renascimento Profissional: Pós-modernismo e a Prática de Arquivo. Informação Arquivística, Rio de Janeiro, v. 2, n. 1, p. 158-187, 2013.

COSTA, Eliandro dos Santos; CAPORALLI, Lucinéia de Araújo.

Preservação de documentos arquivísticos digitais autênticos: estudo do "Projeto de Extensão Eletrônico" da Universidade Estadual de Londrina. Informação Arquivística, Rio de Janeiro, v. 3, n. 2, p. 43-69, jul./dez. 2014.

DANTAS, Célia Medeiros; CORDULA, Flavio Ribeiro; ARAÚJO, Wagner Junqueira. Análise da representação da informação em modelos entidade relacionamento com base em metadados. Archeion Online, João Pessoa, v. 4, n. 1, p. 40-63, jan./jun., 2016.

DORNELES, Sânderson Lopes; CORREAA, Renato Fernandes. Gestão de documentos digitais em aplicações de certificação digital. Informação Arquivística, Rio de Janeiro, v. 2, n. 2, p. 3-31, jul./dez. 2013.

ELIAS, Ezmir Dippe. Gerenciamento eletrônico de documentos (GED): aplicação na Universidade Federal de Santa Catarina. Ágora, Florianópolis, v. 22, n. 45, p. 15-30, 2012.

FERREIRA, Daniela Assis Alves. Tecnologia: fator determinante no advento da sociedade da informação? Perspectivas em Ciência da Informação, Belo Horizonte, v. 8, n. 1, p. 4-11, jan./jun., 2003.

FLORES, Daniel; LAMPERT, Sérgio Renato. As funções de produção, classificação e avaliação de documentos arquivísticos no software Nuxeo Document Management. Informação Arquivística, Rio de Janeiro, v. 2, n. 1, p. 41-64, jan./jun., 2013.

FONTANA, Fabiana Fagundes; FLORES, Daniel; NORA, Fabia Dalla; SANTOS, Henrique Machado dos. Archivematica como ferramenta para acesso e preservação digital à longo prazo. Ágora, Florianópolis, v. 24, n. 48, p. 62-82, 2014.

FREIRE, Isa Maria; CARVALHO, Luciana Moreira; CARVALHO, Mônica Marques; ARANHA, Terezinha de Queiroz. Ampliando o acesso livre à informação: a digitalização do acervo do Núcleo Temático da Seca.

Informação \& Sociedade: Estudos, João Pessoa, v. 18, n. 2, p. 137-142, maio/ago., 2008.

GRÁCIO, José Carlos Abbud; FADEL, Bárbara; VALENTIM, Marta Lígia Pomim. Preservação digital nas instituições de ensino superior: aspectos organizacionais, legais e técnicos. Perspectivas em Ciência da Informação, v. 18, n. 3, p. 111-129, jul./set., 2013.

HAYASHI, Maria Cristina Piumbato Innocentini. Sociologia da ciência, Bibliometria e Cientometria: contribuições para a análise da produção científica. In: SEMINÁRIO DE EPISTEMOLOGIA E TEORIAS DA EDUCAÇÃO, 4., 2012, São Paulo. Anais... São Paulo: UNICAMP, 2012.

Disponível em: <https://www.marilia.unesp.br/Home/Graduacao/PET Biblioteconomia/soc-da-ciencia-pet.pdf > . Acesso em: 12 fev. 2017. 
HERKERT NETTO, Adriana. A contextualização da gestão arquivística de documentos com ênfase na autenticidade e confiabilidade dos documentos digitais. Informação Arquivística, Rio de Janeiro, v. 3, n. 1, p. 2-23, jan./jun., 2014.

LACOMBE, Claudia; RONDINELLI, Rosely Curi. Gestão e preservação de documentos arquivísticos digitais: revisando alguns conceitos que as precedem. Acervo, Rio de Janeiro, v. 29, n. 2, p. 61-73, jul./dez., 2016.

LAMPERT, Sérgio Renato. Os repositórios DSpace e Archivematica para documentos arquivísticos digitais. Acervo, Rio de Janeiro, v. 29, n. 2, p. 143-154, jul./dez., 2016.

LUZ, Marco Antônio da; FLORES, Daniel. A gestão de documentos e a preservação do patrimônio documental em municípios gaúchos: quando a regra é a exceção. Ágora, Florianópolis, v. 24, n. 49, p. 115-142, 2014.

MARQUES, Angélica Alves da Cunha. Pesquisas com temáticas arquivísticas na Ciência da Informação: mapeamento das principais tendências. Encontros Bibli, Florianópolis, v. 16, n. esp. 1 sem., p. 1-22, 2011.

MARQUES, Otacílio Guedes; MANINI, Miriam Paula. Inserção profissional e contribuições teóricas do arquivista na gestão documental do poder judiciário. Ágora, Florianópolis, v. 25, n. 50, p. 61-84, jan./jun., 2015.

MARTINS, Daniela Francescutti. Os desafios da Arquivologia frente à Tecnologia da Informação: uma revisão de literatura. Ágora, Florianópolis, v. 12, n. 26, p. 10-16, 1997.

. As relações entre o usuário e o Guia de Fundos na era digital: um

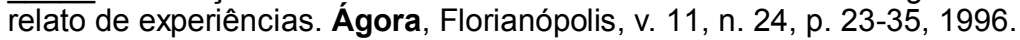
MILLAR, L. A. Archives: principles and practices. $2^{\circ}$. Ed. Londres: Facet Publishing, 2017.

MIGLIAVACCA, Katiuscia Winckler; DUTRA, Moisés Lima. Governo eletrônico, biometria e certificação digital: um estudo de caso no TRE/SC. Ágora, Florianópolis, v. 24, n. 48, p. 242-251, 2014.

NASCIMENTO, Mayara Silva do; SOUSA, Marckson Roberto Ferreira de. A migração de documentos físicos para o ambiente digital no âmbito jurídico.

Archeion Online, João Pessoa, v. 3, n. 2, p. 38-54, jul./dez., 2015.

NEGREIROS, Leandro R.; DIAS, Eduardo W. Automação de arquivos no Brasil: os discursos e seus momentos. Arquivistica.net, Rio de Janeiro, v. 3, n. 1, p. 38-53, jan./jun., 2007.

A prática arquivística: os métodos da disciplina e os documentos tradicionais e contemporâneos. Perspectivas em Ciência da Informação, v. 13, p. 2-19, 2008.

OHIRA, Maria de Lourdes Blatt; DAVOK, Delsi Fries; SCHENKEL, Marília Beatriz de Castro. Proposta para criação do sistema de arquivos da Universidade do Estado de Santa Catarina: trajetória, desafios e perspectivas. Informação \& Sociedade: Estudos, João Pessoa, v. 18, n. 2, p. 143-154, maio/ago., 2008. 
ROCHA, Claudia Lacombe; SILVA, Margareth da. Padrões para garantir a preservação e o acesso aos documentos digitais. Acervo, Rio de Janeiro, v. 20, n. 1-2, p. 113-124, jan./dez., 2007.

. Carta para a preservação do patrimônio arquivístico digital brasileiro.

Acervo, Rio de Janeiro, v. 17, n. 2, p. 131-140, jul./dez., 2004.

RONDINELLI, Rosely Curi. Gerenciamento arquivístico de documentos eletrônicos. 4. ed. Rio de Janeiro: FGV, 2005.

SALES, Luana Farias; SAYÃO, Luís Fernando. O impacto da curadoria digital dos dados de pesquisa na comunicação científica. Encontros Bibli, Florianópolis, v. 17, n. esp. 2, p. 118-135, 2012.

SANTA ANNA, Jorge. $O$ arquivista como gestor de recurso informacionais: uma reflexão acerca dos novos modelos de gestão. Ágora, Florianópolis, v. 25, n. 51, p. 77-100, jul./dez., 2015.

SANTOS, Henrique Machado dos; FLORES, Daniel. O documento arquivístico digital enquanto fonte de pesquisa. Perspectivas em Ciência da Informação, Belo Horizonte, v. 21, n. 4, p. 1-17, out./dez., 2016.

. Preservação de documentos arquivísticos digitais: reflexões sobre as estratégias de emulação. Encontros Bibli, Florianópolis, v. 20, n. 43, p. 3-19, maio/ago., 2015.

. Preservação de documentos arquivísticos digitais autênticos:

reflexões e perspectivas. Acervo, Rio de Janeiro, v. 28, n. 1, p. 241-253, jan./jun., 2015.

. Interoperabilidade entre Repositórios Arquivísticos Digitais

Confiáveis. Ágora, Florianópolis, v. 60, p. 213-234, jan./jul., 2020.

SANTOS, V. B. Preservação de documentos arquivísticos digitais. Ciência da Informação (Online), v. 41, p. 114-126, 2014.

SANTOS JUNIOR, Roberto Lopes dos; NUNES, Vanderson Monteiro.

Estudo da preservação digital dos videogames sob o viés da arquivologia. Informação \& Sociedade: Estudos, João Pessoa, v. 26, n. 3, p. 31-46, set./dez., 2016.

SCHAFER, M. B.; CONSTANTE, S. E. Políticas e estratégias para a preservação da informação digital. Ponto de Acesso (UFBA), v. 6 , p. 108-140, 2012.

.; LIMA, Eliseu dos Santos. A classificação e a avaliação de documentos: análise de sua aplicação em um sistema de gestão de documentos arquivísticos digitais. Perspectivas em Ciência da Informação, Belo Horizonte, v. 17, n. 3, p. 137-154, jul./set., 2012.

SILVA, Ana Paula Araújo Cabral da. SEER e PDF/A na preservação do periódico Archivos Rio-Grandense de Medicina: relato de experiência.

Encontros Bibli, Florianópolis, v. 17, n. esp. 2, p. 227-237, 2012. 
SILVA, Sérgio Conde de Albite. Decifra-me ou te devoro: desafios no uso de tecnologias para preservação e acesso em arquivos. Encontros Bibli, Florianópolis, v. 16, n. 1, p. 40-59, 2011.

THOMAZ, Kátia P. Gestão e preservação de documentos eletrônicos de arquivo: revisão de literatura - parte 2. Arquivística.net, Rio de Janeiro, v. 2, n. 1, p. 114-131, jan./jun., 2006.

AZEVEDO JUNIOR, Márcio Antonio. Sistema de Processos Administrativos (SPA) do projeto "UFSC sem papel" sob a ótica dos servidores do Centro de Ciências Agrárias. Ágora, Florianópolis, v. 24, n. 49, p. 225-256, 2014.

. O PDF/A na gestão de documentos arquivísticos. Ágora,

Florianópolis, v. 21, n. 43, p. 73-79, 2011. 
APÊNDICE - Artigos científicos encontrados nos periódicos pesquisados distribuídos nas terminologias à coleta de dados.

\begin{tabular}{|c|c|c|}
\hline ORDEM & REFERÊNCIA ADAPTADA & TERMINOLOGIA ATRIBUIDA \\
\hline \multicolumn{3}{|c|}{ ACERVO (8) } \\
\hline 1 & $\begin{array}{l}\text { ABREU, J. P. L. Aprender a ler entre } \\
\text { bits: autenticidade em arquivos } \\
\text { pessoais digitais. (2016) }\end{array}$ & Avanços Tecnológicos \\
\hline 2 & $\begin{array}{l}\text { LACOMBE, C.; RONDINELLI, R. C. } \\
\text { Gestão e preservação de documentos } \\
\text { arquivísticos digitais: revisando alguns } \\
\text { conceitos que as precedem. (2016) }\end{array}$ & Preservação de Documentos \\
\hline 3 & \begin{tabular}{|lrrr} 
LAMPERT, & S. & R. Os repositórios \\
DSpace & e & Archivematica & para \\
documentos & arquivísticos digitais. & $(2016)$
\end{tabular} & Preservação de Documentos \\
\hline 4 & $\begin{array}{l}\text { LOPES, A. S. P.; FLORES, D. } \\
\text { Patrimônio documental: a preservação } \\
\text { digital em longo prazo. (2016) }\end{array}$ & Preservação de Documentos \\
\hline 5 & 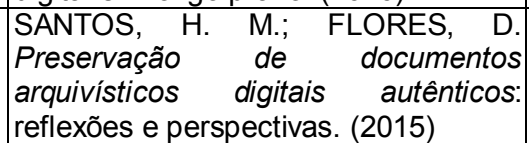 & Preservação de Documentos \\
\hline 6 & $\begin{array}{l}\text { BESSER, H. Longevidade digital. } \\
(2010)\end{array}$ & Preservação de Documentos \\
\hline 7 & $\begin{array}{l}\text { ROCHA, C. L.; SILVA, M. Padrões para } \\
\text { garantir a preservação e o acesso aos } \\
\text { documentos digitais. (2007) }\end{array}$ & Preservação de Documentos \\
\hline 8 & $\begin{array}{l}\text { ROCHA, C. L.; SILVA, M. Carta para a } \\
\text { preservação do patrimônio arquivístico } \\
\text { digital brasileiro. (2004) }\end{array}$ & Preservação de Documentos \\
\hline \multicolumn{3}{|c|}{ ÁGORA (12) } \\
\hline 9 & $\begin{array}{l}\text { MARTINS, D. F. Os desafios da } \\
\text { Arquivologia frente à Tecnologia da } \\
\text { Informação: uma revisão de literatura. } \\
\text { (1997) }\end{array}$ & Avanços Tecnológicos \\
\hline 10 & $\begin{array}{l}\text { MARTINS, D. F. As relações entre o } \\
\text { usuário e o Guia de Fundos na era } \\
\text { digital: um relato de experiências. (1996) }\end{array}$ & Avanços Tecnológicos \\
\hline 11 & $\begin{array}{l}\text { MIGLIAVACCA, K. W.; DUTRA, M. L. } \\
\text { Governo eletrônico, biometria e e } \\
\text { certificação digital: um estudo de caso } \\
\text { no TRE/SC. (2014) }\end{array}$ & Certificação Digital \\
\hline 12 & $\begin{array}{l}\text { ANJOS, C. L. B.; FELIPE, A. A. C. } \\
\text { Gestão documental em unidades de } \\
\text { informação: uma análise do arquivo } \\
\text { da Fundação Norte-Rio-Grandense de } \\
\text { Pesquisa de Cultura } \\
\text { FUNPEC. (2014) }\end{array}$ & GED \\
\hline
\end{tabular}


Continuação

\begin{tabular}{|c|c|c|}
\hline \multicolumn{2}{|c|}{\begin{tabular}{l|l} 
ORDEM & REFERÉNCIA ADAPTADA
\end{tabular}} & TERMINOLOGIA ATRIBUIDA \\
\hline \multicolumn{3}{|c|}{ ÁGORA (12) } \\
\hline 13 & $\begin{array}{l}\text { ELIAS, E. D.; MERINO, E. A. D.; PINTOU, } \\
\text { A. L.; PINTO, M. D. S.; BATISTA, V. J. } \\
\text { Aplicação da ergonomiar na } \\
\text { operacionalização do Gerenciamento } \\
\text { Eletrônico de Documentos (GED) } \\
\text { avaliação prática. (2014) }\end{array}$ & GED \\
\hline 14 & $\begin{array}{l}\text { SILVA, S. C. L.; BEDIN, S. P. M. } \\
\text { Sistemas de gestão documental em } \\
\text { Florianópolis: análise de funcionalidades } \\
\text { baseada nos requisitos do e-Arq Brasil. } \\
\text { (2014) }\end{array}$ & GED \\
\hline 15 & $\begin{array}{l}\text { VITAL, L. P.; AZEVEDO JUNIOR, M. A. } \\
\text { Sistema de Processos Administrativos } \\
\text { (SPA) do projeto "UFSC sem papel" sob } \\
\text { a ótica dos servidores do Centro de } \\
\text { Ciências Agrárias. (2014) }\end{array}$ & GED \\
\hline 16 & $\begin{array}{l}\text { ELIAS, E. D. Gerenciamento eletrônico } \\
\text { de documentos (GED): aplicação na } \\
\text { Universidade Federal de Santa Catarina. } \\
\text { (2012) }\end{array}$ & GED \\
\hline 17 & $\begin{array}{l}\text { CATTELAN, P. Winbusca-GED: } \\
\text { construção do banco de dados do } \\
\text { Arquivo Histórico para o Memorial do } \\
\text { Rio Grande do Sul. (2000) }\end{array}$ & GED \\
\hline 18 & $\begin{array}{l}\text { FONTANA, F. F.; FLORES, D.; } \\
\text { NORA, F. D.; SANTOS, H. M. } \\
\text { Archivematica como ferramenta para } \\
\text { acesso e preservação digital à longo } \\
\text { prazo. (2014) }\end{array}$ & Preservação de Documentos \\
\hline 19 & $\begin{array}{l}\text { SOARES, S. M. V. O microfilme e o } \\
\text { digital: as duas faces da preservação. } \\
(2011)\end{array}$ & Preservação de Documentos \\
\hline 20 & $\begin{array}{l}\text { VITAL. L. P. O PDF/A na gestão de } \\
\text { documentos arquivísticos. (2011) }\end{array}$ & Preservação de Documentos \\
\hline & ARCHEION ONLINE & \\
\hline 21 & $\begin{array}{l}\text { NASCIMENTO, M. S.; SOUSA, M. R. } \\
\text { F. A migração de documentos físicos } \\
\text { para o ambiente digital no âmbito } \\
\text { jurídico. (2015) }\end{array}$ & GED \\
\hline 22 & $\begin{array}{l}\text { OLIVEIRA, C. T. O gerenciamento } \\
\text { eletrônico de documentos sob a ótica } \\
\text { da representação da informação } \\
\text { arquivística. (2014) }\end{array}$ & GED \\
\hline
\end{tabular}


Continuação

\begin{tabular}{|c|c|c|}
\hline ORDEM & REFERÉNCIA ADAPTADA & TERMINOLOGIA ATRIBUIDA \\
\hline & ARCHEION ONLINE & \\
\hline 23 & $\begin{array}{l}\text { DANTAS, C. M.; CORDULA, F. R.; } \\
\text { ARAÚJO, W. J. Análise da da } \\
\text { representação da informação em } \\
\text { modelos entidade relacionamento } \\
\text { com base em metadados. (2016) }\end{array}$ & Tecnologia e Sociedade \\
\hline & INFORMAÇÃO ARQUIVÍs & TICA (6) \\
\hline 24 & $\begin{array}{l}\text { HERKERT NETTO, A. } \\
\text { contextualização da gestão arquivística } \\
\text { de documentos com ênfase na } \\
\text { autenticidade e confiabilidade dos } \\
\text { documentos digitais. (2014) }\end{array}$ & Certificação Digital \\
\hline 25 & $\begin{array}{l}\text { DORNELES, S. L.; CORRËA, R. F. } \\
\text { Gestão de documentos digitais em } \\
\text { aplicações de certificação digital. (2013) }\end{array}$ & Certificação Digital \\
\hline 26 & $\begin{array}{l}\text { FLORES, D.; LAMPERT, S. R. As } \\
\text { funções de produção, classificação e } \\
\text { avaliação de documentos arquivisticos } \\
\text { no software Nuxeo Document } \\
\text { Management. (2013) }\end{array}$ & GED \\
\hline 27 & $\begin{array}{l}\text { LUZ, C. A interoperabilidade na } \\
\text { preservação da informação arquivística: } \\
\text { os metadados e a descrição. (2016) }\end{array}$ & Preservação de Documentos \\
\hline 28 & $\begin{array}{l}\text { COSTA, E. S.; CAPORALLI, L. A. } \\
\text { Preservação de documentos } \\
\text { arquivísticos digitais autênticos: } \\
\text { estudo do "Projeto de Extensão } \\
\text { Eletrônico" da Universidade Estadual } \\
\text { de Londrina. (2014) }\end{array}$ & Preservação de Documentos \\
\hline 29 & $\begin{array}{l}\text { SANTOS, H. M.; FLORES, D. } \\
\text { As estratégias de emulação como } \\
\text { fundamento para a preservação de } \\
\text { objetos digitais interativos: a garantia } \\
\text { de acesso fidedigno em longo prazo. } \\
\text { (2014) }\end{array}$ & Preservação de Documentos \\
\hline & ENCONTROS BIBLI & 12) \\
\hline 30 & $\begin{array}{l}\text { SALES, L. F.; SAYÃO, L. F. } \\
\text { O impacto da curadoria digital dos } \\
\text { dados de pesquisa na comunicação } \\
\text { científica. (2012) }\end{array}$ & Avanços Tecnológicos \\
\hline 31 & 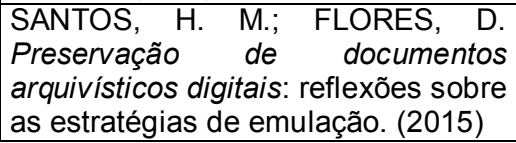 & Preservação de Documentos \\
\hline
\end{tabular}


Continuação

\begin{tabular}{|c|c|c|}
\hline RDEM & REFERÊNCIA ADAPTADA & TERMINOLOGIA ATRIBUIDA \\
\hline \multicolumn{3}{|c|}{ ENCONTROS BIBLI (12) } \\
\hline 32 & $\begin{array}{l}\text { ALMEIDA, M. B.; CENDRÓN, B. V.; } \\
\text { SOUZA, R. R. Metodologia para } \\
\text { implantação de programas de } \\
\text { preservação de documentos digitais a } \\
\text { longo prazo. (2012) }\end{array}$ & Preservação de Documentos \\
\hline 33 & $\begin{array}{l}\text { MACEVICIUTE, E. Long-term digital } \\
\text { preservation and scholarly } \\
\text { communication. (2012) }\end{array}$ & Preservação de Documentos \\
\hline 34 & $\begin{array}{l}\text { SILVA, A. P. A. C. SEER e } \\
\text { PDF/A na preservação do periódico } \\
\text { Archivos Rio-Grandense de Medicina: } \\
\text { relato de experiência. (2012) }\end{array}$ & Preservação de Documentos \\
\hline 35 & $\begin{array}{l}\text { YAMAOKA, E. J.; GAUTHIER, F. O. } \\
\text { Ontologia de dependência tecnológica } \\
\text { de documentos digitais: instrumento } \\
\text { de apoio à preservação digital. (2012) }\end{array}$ & Preservação de Documentos \\
\hline 36 & $\begin{array}{l}\text { BAHIA, E. M. S.; SANTOS, R. N. M.; } \\
\text { BLATTMANN, U. Estudo bibliométrico } \\
\text { sobre preservação digital: Library and } \\
\text { Information Science Abstracts - LISA. } \\
\text { (2011) }\end{array}$ & Preservação de Documentos \\
\hline 37 & $\begin{array}{l}\text { OLIVEIRA, R. T. Políticas } \\
\text { arquivísticas e suas implicações na } \\
\text { preservação, no acesso e no uso dos } \\
\text { documentos. (2011) }\end{array}$ & Preservação de Documentos \\
\hline 38 & $\begin{array}{l}\text { SILVA, S. C. A. Decifra-me ou te } \\
\text { devoro: desafios no uso de } \\
\text { tecnologias para preservação e } \\
\text { acesso em arquivos. (2011) }\end{array}$ & Preservação de Documentos \\
\hline 39 & $\begin{array}{l}\text { SAYÃO, L. F. Uma face dos metadados: } \\
\text { informações para a gestão da } \\
\text { preservação digital (2010). }\end{array}$ & Preservação de Documentos \\
\hline 40 & $\begin{array}{l}\text { RONCAGLIO, C.; SZVARÇA, D. R.; } \\
\text { BOJANOSKI, S. F. Arquivos, gestão } \\
\text { de documentos e informação. (2004) }\end{array}$ & Preservação de Documentos \\
\hline 41 & $\begin{array}{l}\text { BAHIA, E. M. S. Preservação e } \\
\text { conservação documental em acervo } \\
\text { de manuscritos. (2002) }\end{array}$ & Preservação de Documentos \\
\hline \multicolumn{3}{|c|}{ INFORMAÇÃO \& SOCIEDADE: ESTUDOS (10) } \\
\hline 42 & $\begin{array}{l}\text { ARAÚJO, R. M.; ARAÚJO, M. A. D.; } \\
\text { ALLOUFA, J. M. L.; LOPES, A. O. B. } \\
\text { Governo eletrônico: um estudo sobre } \\
\text { as possibilidades de participação do } \\
\text { cidadão. (2013) }\end{array}$ & Avanços Tecnológicos \\
\hline
\end{tabular}


Continuação

\begin{tabular}{|c|c|c|}
\hline RDEM & REFERÊNCIA ADAPTADA & TERMINOLOGIA ATRIBUIDA \\
\hline & INFORMAÇÃO \& SOCIEDADE: & ESTUDOS (10) \\
\hline 43 & $\begin{array}{l}\text { OHIRA, M. L. B.; DAVOK, D. F.; } \\
\text { SCHENKEL, M. B. C. Proposta para } \\
\text { criação do sistema de arquivos da } \\
\text { Universidade do Estado de Santa } \\
\text { Catarina: trajetória, desafios e } \\
\text { perspectivas. (2008) }\end{array}$ & Avanços Tecnológicos \\
\hline 44 & $\begin{array}{l}\text { DIAS, G. A.; DELFINO JUNIOR, J. B.; } \\
\text { SILVA, J. W. M. Open Journal } \\
\text { Systems - OJS: migrando um } \\
\text { periódico científico eletrônico para um } \\
\text { sistema automatizado de gerência e } \\
\text { publicação de periódicos científicos } \\
\text { eletrônicos. (2007) }\end{array}$ & Avanços Tecnológicos \\
\hline 45 & $\begin{array}{l}\text { LOURENÇO, C. A. Metadados: } \\
\text { o grande desafio na organização da } \\
\text { web. (2007) }\end{array}$ & Avanços Tecnológicos \\
\hline 46 & \begin{tabular}{|l|} 
GARCIA, R. M. Governo eletrônico, \\
informação e e competência em \\
informação. (2006)
\end{tabular} & Avanços Tecnológicos \\
\hline 47 & $\begin{array}{l}\text { ALONSO, L. B. N.; FERNEDA, E.; } \\
\text { BRAGA, L. V. Governo eletrônico e } \\
\text { políticas públicas: análise sobre o } \\
\text { uso da certificação digital no Brasil. } \\
\text { (2011) }\end{array}$ & Certificação Digital \\
\hline 48 & $\begin{array}{l}\text { SANTOS JUNIOR, R. L.; NUNES, V. } \\
\text { M. Estudo da preservação digital dos } \\
\text { videogames sob } \\
\text { arquivologia. (2016) }\end{array}$ & Preservação de Documentos \\
\hline 49 & $\begin{array}{l}\text { SAYÃO, L. F.; SALES, L. F. } \\
\text { Curadoria digital: um novo patamar } \\
\text { para preservação de dados digitais } \\
\text { de pesquisa. (2012) }\end{array}$ & Preservação de Documentos \\
\hline 50 & $\begin{array}{l}\text { CARVALHO, M. A.; OTERO, M. M. } \\
\text { D. F.; BARBOSA, J. P. Acesso e } \\
\text { preservação da "Coleção Oficina } \\
\text { Guaianases de Gravura". (2006) }\end{array}$ & Preservação de Documentos \\
\hline 51 & \begin{tabular}{|l|} 
FREIRE, I. M.; CARVALHO, L. M.; \\
CARVALHO, M. M.; ARANHA, T. Q. \\
Ampliando o acesso livre à \\
informação: a digitalização do acervo \\
do Núcleo Temático da Seca. (2008)
\end{tabular} & Tecnologia e Sociedade \\
\hline
\end{tabular}


Continuação

\begin{tabular}{|c|c|c|}
\hline RDEM & REFERÉNCIA ADAPTADA & TERMINOLOGIA ATRIBUIDA \\
\hline \multicolumn{3}{|c|}{ PERSPECTIVAS EM CIÊNCIA DA INFORMAÇÃO (9) } \\
\hline 52 & 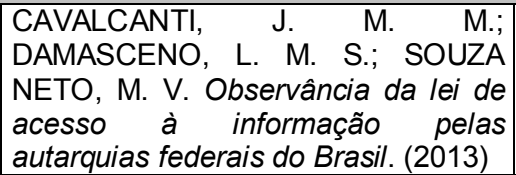 & Avanços Tecnológicos \\
\hline 53 & $\begin{array}{l}\text { NEGREIROS, L. R.; DIAS, E. J. W. A } \\
\text { prática arquivistica: os métodos da } \\
\text { disciplina e os documentos tradicionais } \\
\text { e contemporâneos. (2008) }\end{array}$ & Avanços Tecnológicos \\
\hline 54 & $\begin{array}{l}\text { SCHÄFER, M. B.; LIMA, E. S. } \\
\text { A classificação e a avaliação de } \\
\text { documentos: análise de sua aplicação } \\
\text { em um sistema de gestão de } \\
\text { documentos arquivísticos digitais. } \\
\text { (2012) }\end{array}$ & GED \\
\hline 55 & 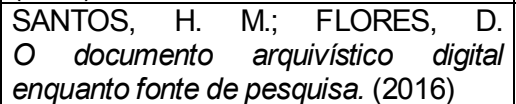 & Preservação de Documentos \\
\hline 56 & $\begin{array}{l}\text { SANTOS, H. M.; FLORES, D. Políticas } \\
\text { de preservação digital para } \\
\text { documentos arquivisticos. (2015) }\end{array}$ & Preservação de Documentos \\
\hline 57 & 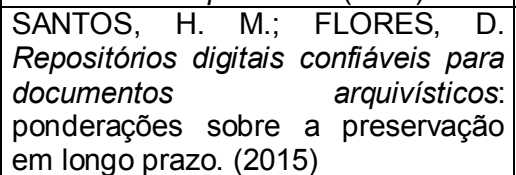 & Preservação de Documentos \\
\hline 58 & $\begin{array}{l}\text { GRÁCIO, J. C. A.; FADEL, B.; } \\
\text { VALENTIM, M. L. P. Preservação } \\
\text { digital nas instituições de ensino } \\
\text { superior: aspectos organizacionais, } \\
\text { legais e técnicos. (2013) }\end{array}$ & Preservação de Documentos \\
\hline 59 & \begin{tabular}{|lrrr} 
POSSI, M. A.; & OLIVEIRA, A. & P.; \\
MOREIRA, & A.; & MENDES, & F.; \\
QUEIROZ, J. M. & Ambiente para busca \\
e visualização & de & documentos \\
históricos & & & na \\
web. (2011) & & & \\
\end{tabular} & Preservação de Documentos \\
\hline 60 & \begin{tabular}{|lcrr} 
THOMAZ, & K. & P. & Documentos \\
eletrônicos & de caráter arquivístico: \\
fatores & condicionantes r da \\
preservação. & (2005) &
\end{tabular} & Preservação de Documentos \\
\hline
\end{tabular}


Continuação

\begin{tabular}{|c|c|c|}
\hline ORDEM & REFERÊNCIA ADAPTADA & TERMINOLOGIA ATRIBUIDA \\
\hline & TRANSINFORMAÇÃO & (2) \\
\hline 61 & $\begin{array}{l}\text { TEIXEIRA, W. A. M. Ações de } \\
\text { conservação e preservacão da } \\
\text { memória no contexto digital. (2002) }\end{array}$ & Preservação de Documentos \\
\hline 62 & $\begin{array}{l}\text { CABRAL, A. M. R. Tecnologia digital } \\
\text { em bibliotecas } \\
\text { arquivos. (2002) }\end{array}$ & Avanços Tecnológicos \\
\hline
\end{tabular}

Fonte: Autores da pesquisa, 2017. 